(2) OPEN ACCESS

\title{
Effect of asthma education on health outcomes in children: a systematic review
}

\author{
Wen-Yi Liu, ${ }^{1,2,3}$ Zhu Liduzi Jiesisibieke, ${ }^{2}$ Tao-Hsin Tung (1) ${ }^{4}$
}

- Additional supplemental material is published online only. To view, please visit the journal online (http://dx.doi. org/10.1136/archdischild2021-323496)

${ }^{1}$ Department of Health Policy Management, Bloomberg School of Public Health, Johns Hopkins University, Baltimore, Maryland, USA

${ }^{2}$ Institute for Hospital Management, Tsing Hua University, Shenzhen Campus, China

${ }^{3}$ Shanghai Bluecross Medical Science Institute, Shanghai, China

${ }^{4}$ Evidence-based Medicine Center, Taizhou Hospital of Zhejiang Province Affiliated to Wenzhou Medical University, Linhai, Zhejiang Province, China

\section{Correspondence to}

Dr Tao-Hsin Tung, Taizhou Hospital of Zhejiang Province, Linhai 317000, Zhejiang, China; ch2876@gmail.com

Received 9 November 2021 Accepted 8 February 2022
Check for updates

(C) Author(s) (or their employer(s)) 2022. Re-use permitted under CC BY-NC. No commercial re-use. See rights and permissions. Published by BMJ.

To cite: Liu W-Y, Jiesisibieke ZL, Tung T-H. Arch Dis Child Epub ahead of print: [please include Day Month Year]. doi:10.1136/ archdischild-2021-323496

\begin{abstract}
Background It remains unknown whether childoriented asthma education is associated with better health outcomes. This meta-analysis investigated the effects of asthma education on hospitalisation and emergency department and clinic visits.
\end{abstract}

Methods We searched the Cochrane Library, PubMed and EMBASE for relevant studies from inception to 4 July 2021, and selected studies that reported hospitalisation or emergency department or clinic visits as outcomes. The participants were only children. Two authors independently selected the studies, assessed the quality of the included studies and retrieved the data. A third senior author was engaged to resolve disagreements. Fifteen longitudinal studies were included for the systematic review and meta-analysis. Preferred Reporting Items for Systematic Reviews and Meta-Analyses (PRISMA) 2020 was used as the standard of reporting (PRISMA registration ID is 284509).

Findings Compared with the control group, the asthma education group had 54\% lower hospitalisation risk (95\% Cl 0.32 to 0.66), and $31 \%$ lower emergency department visit risk ( $95 \% \mathrm{Cl} 0.59$ to 0.81 ). Sensitivity analysis showed that the asthma education group had a reduced clinic visit risk (risk ratio $(R R)=0.80,95 \% \mathrm{Cl}$ 0.67 to 0.97 ). Subgroup analysis showed that asthma education involving both children and parents/guardians was associated with fewer hospitalisations ( $R R=0.38$, $95 \% \mathrm{Cl} 0.24$ to 0.59 ) and emergency department visits ( $R R=0.69,95 \% \mathrm{Cl} 0.57$ to 0.83 ). Asthma education in hospitals or non-hospitals can reduce the risk of hospitalisation and emergency department visits. However, only education in the hospitals was associated with the reduction of clinical visits $(R R=0.45,95 \% \mathrm{Cl}$ 0.22 to 0.92 ).

Interpretation Education is effective for controlling asthma, especially for reducing hospitalisation and emergency department and clinic visits. Education involving both children and parents/guardians is more effective than that involving only children. The setting of asthma education does not impact its effect to a large extent.

\section{INTRODUCTION}

Asthma is a common chronic condition in children with symptoms such as shortness of breath, oppression in the chest, coughing and wheezing, as well as episodes of sudden aggravation. ${ }^{12}$ It is widespread and affects 6.1 million children globally, which has a large impact on the quality of life and results in significant death. ${ }^{2}{ }^{3}$ Asthma-related hospitalisation may also have an impact on educational achievements of children, ${ }^{4}$ and asthma in children is significantly associated with later risk of becoming obese ${ }^{5}$ which is a risk factor of several chronic diseases. ${ }^{6-8}$ In the context of COVID-19, being alert and following the treatment guidelines, as well as implementing preventive measures, are of great importance for improving the outcomes among children with asthma. ${ }^{9}$ Asthma education is one of the preventive measures. ${ }^{10}$ The participants and the settings of asthma education vary; some sessions may include only children, ${ }^{11}$ while some include both children and parents/guardians. ${ }^{12}$ The setting of asthma education also differs. ${ }^{13}{ }^{14}$ Some prior studies have shown that asthma education targeted at children can reduce unscheduled visits and hospitalisations. ${ }^{15-17}$ One study found that asthma education was a useful tool for controlling asthma. However, it is not significantly effective in reducing healthcare utilisation when compared with usual care. ${ }^{18}$ Another study found no change in emergency department (ED) visits and hospitalisations after paediatric asthma education. ${ }^{19}$

As a result, it is still unclear whether asthma education is useful for controlling asthma, and the impact of participants and the setting has also not been established. We conducted this systematic review and metaanalysis to assess the overall effects of child-centred asthma education on health outcomes, including hospitalisations and ED and clinic visits.

\section{MATERIALS AND METHODS}

Literature search

We performed this meta-analysis to study the effect of asthma education on hospitalisation and emergency room and clinic visits of children. The Cochrane Library, PubMed and EMBASE were searched for relevant studies from inception to 4 July 2021. The search string was "(child OR pediatric OR kid) AND (asthma) AND education AND (hospitalization OR emergency department visit OR urgent physician visit OR outpatient)" for all three databases (online supplemental table 1). The language was not restricted. Based on the PRISMA 2020 statement (Preferred Reporting Items for Systematic Reviews and Meta-Analyses), ${ }^{20}$ we also conducted additional research on relevant studies (figure 1). The protocol for this systematic review was recorded in PROSPERO with identification number 284509 .

\section{Inclusion criteria and exclusion criteria \\ Types of participants}

The participants were children. Studies that recorded the health outcomes of children and adults were not included. The participants had to 


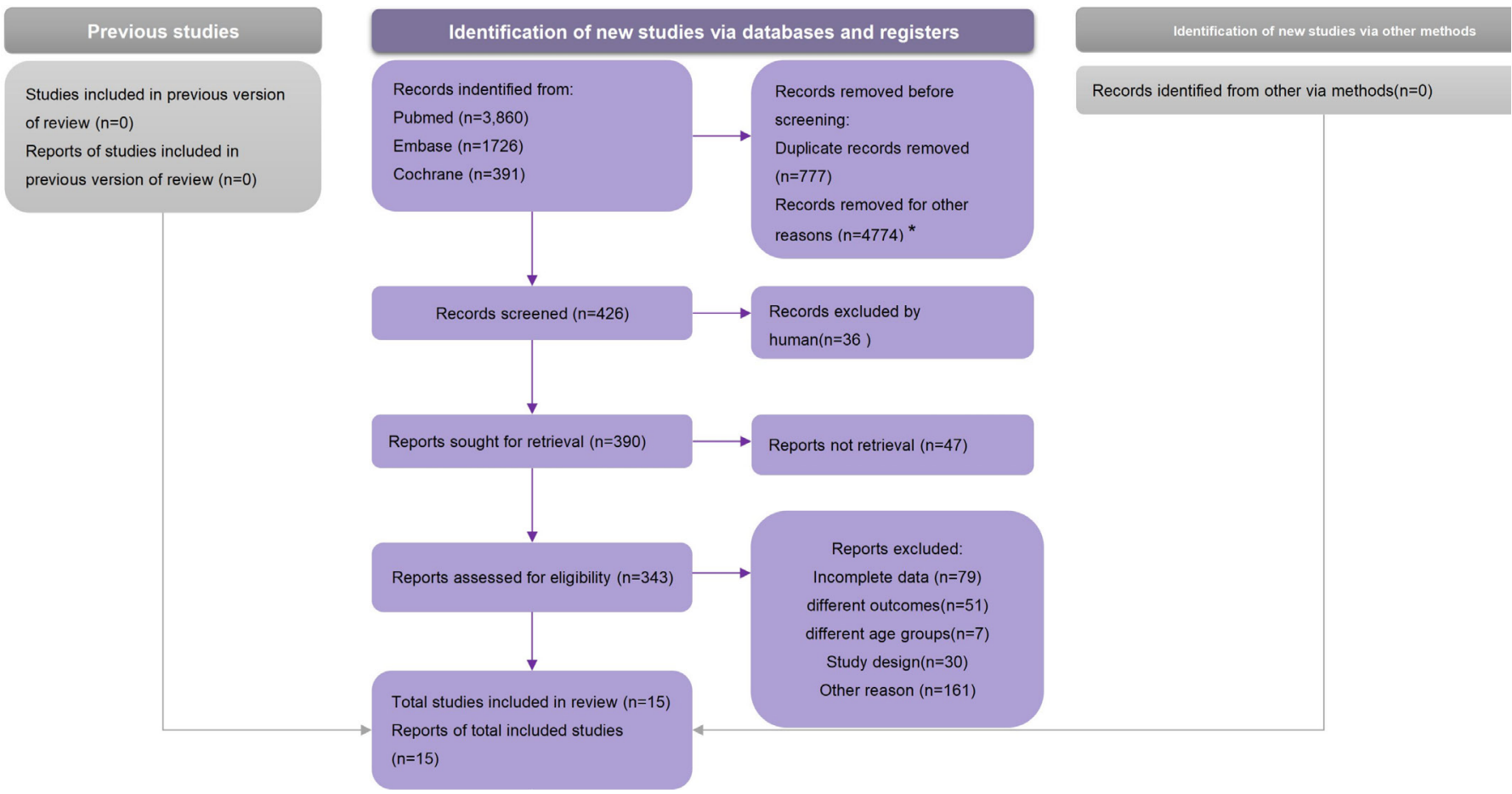

Figure 1 Preferred Reporting Items for Systematic Reviews and Meta-Analyses flow chart.

be diagnosed with asthma, but hospitalisation in the past was not a restriction.

\section{Asthma education intervention}

We did not limit the tools, settings and instructors for asthma education. Some of the included studies focused on drugs, and others focused on the triggers of asthma in the environment. All the included studies assessed the basic information of asthma, such as causes and treatment. The education could involve just children, caregivers, or both children and caregivers.

\section{Outcomes}

We generally included three outcomes, which are hospitalisation, emergency room visits and clinic visits. The outcomes were recorded as frequency instead of the number of patients. The clinic visit could be either routine or urgent.

\section{Study design}

To investigate the causal relationship between asthma education and health outcomes, longitudinal studies were included. Thus, the outcomes before and after the intervention were collected.

\section{Data extraction and quality assessment}

Two independent reviewers, Wen-Yi Liu and Zhu Liduzi Jiesisibieke, screened the studies for inclusion. Finally, 15 studies met the criteria. Author, study year, country, interventions, tools, outcomes, sample, educators, setting and outcomes were extracted from the 15 included studies. The Newcastle-Ottawa Scale was applied to analyse the quality of the included studies. For cohort studies, the selection of study groups (S), comparability $(\mathrm{C})$ and outcome assessment $(\mathrm{O})$ were used. ${ }^{21}$ For casecontrol studies, apart from the selection of participants (S) and comparability (C), exposure (E) was also used. ${ }^{22}$ We used funnel plots and Egger's test to assess the publication bias of the included studies.

\section{Characteristics of the excluded studies}

During the screening, some studies were excluded because of incomplete data, and others were excluded for their study design ${ }^{23-28}$; we only included longitudinal studies. Some studies were excluded because the participants of asthma education were not only children. ${ }^{29-31}$ We just included studies that met our inclusion criteria.

\section{Statistical analysis}

Stata V.16.0 SE was used for the statistical analysis, and we presented the risk of health outcomes as risk ratio (RR) with 95\% CI and analysed heterogeneity using the $\mathrm{I}^{2}$ statistic. The $\mathrm{I}^{2}$ statistic is an analytical test that measures the degree of variation between studies due to heterogeneity rather than by chance alone. $\mathrm{I}^{2}$ values of $50 \%$ or more represent substantial heterogeneity. $^{32}$

\section{RESULTS}

\section{Characteristics of the included studies}

The screening process is illustrated in figure 1 . After removing the duplicates, 5200 studies were identified. We referred to the newest checklist of PRISMA to investigate whether the studies met our inclusion criteria. Overall, this study included 15 longitudinal studies, and after detailed analysis, their characteristics are shown in online supplemental table 2. These papers were published between 1991 and 2020, and 10 of them had been conducted in the USA. The outcomes of 12 papers included hospitalisations, and those of 13 papers were emergency visits as suitable outcomes; only six studies were related to the change in clinic visits. There were two main settings: medical establishments, such as hospitals and clinics, and other places. In the early studies, the most common teaching tools were sessions and handouts, so the asthma education all given face to face. Later, technological advancements enabled the internet and videos as useful tools, some of the education courses were online. The 
Table 1 GRADE summary of findings

\begin{tabular}{|c|c|c|c|c|c|c|}
\hline \multicolumn{7}{|c|}{ Effect of asthma education on health outcomes in children } \\
\hline \multicolumn{7}{|c|}{$\begin{array}{l}\text { Patient or population: children with asthma } \\
\text { Setting: USA, France, Spain } \\
\text { Intervention: asthma education } \\
\text { Comparison: not receiving asthma education }\end{array}$} \\
\hline \multirow[t]{2}{*}{ Outcomes } & \multicolumn{2}{|c|}{$\begin{array}{l}\text { Anticipated absolute effects* } \\
(95 \% \mathrm{Cl})\end{array}$} & \multirow[t]{2}{*}{$\begin{array}{l}\text { Relative effect } \\
(95 \% \mathrm{Cl})\end{array}$} & \multirow[t]{2}{*}{$\begin{array}{l}\text { No of participants } \\
\text { (studies) }\end{array}$} & \multirow[t]{2}{*}{$\begin{array}{l}\text { Quality of the evidence } \\
\text { (GRADE) }\end{array}$} & \multirow[t]{2}{*}{ Comments } \\
\hline & Risk in control & Risk in experiment & & & & \\
\hline Risk of hospitalisation & 814 per 1000 & 360 per 1000 & $\begin{array}{l}\text { RR } 0.46 \\
(0.32 \text { to } 0.66)\end{array}$ & 2122 & $\begin{array}{l}\oplus \oplus \oplus \bigcirc \\
\text { Low }\end{array}$ & NA \\
\hline Risk of ED visits & 1462 per 1000 & 864 per 1000 & $\begin{array}{l}\text { RR } 0.69 \\
\text { (0.59 to } 0.81)\end{array}$ & 2040 & $\begin{array}{l}\oplus \oplus \oplus \bigcirc \\
\text { Moderate }\end{array}$ & NA \\
\hline Risk of clinic visits & 1043 per 1000 & 1004 per 1000 & $\begin{array}{l}\text { RR } 0.79 \\
\text { (0.67 to } 0.97)\end{array}$ & 438 & $\begin{array}{l}\oplus \oplus \oplus \bigcirc \\
\text { Low }\end{array}$ & NA \\
\hline
\end{tabular}

GRADE Working Group grades of evidence:

High quality: we are very confident that the true effect lies close to that of the estimate of the effect.

Low quality: our confidence in the effect estimate is limited. The true effect may be substantially different from the estimate of the effect.

Very low quality: we have very little confidence in the effect estimate. The true effect is likely to be substantially different from the estimate of effect.

*The risk in the intervention group (and its $95 \% \mathrm{Cl}$ ) is based on the assumed risk in the comparison group and the relative effect of the intervention (and its $95 \% \mathrm{Cl}$ ).

ED, emergency department; GRADE, Grades of Recommendation, Assessment,Development, and Evaluation; RR, risk ratio.

risks of bias and supporting evidence are shown in table 1 and online supplemental figure 1 . All of these studies are longitudinal; thus, time and other factors may affect the outcomes, which is a bias that cannot be ignored.

\section{Assessment of the effect of asthma education on hospitalisation}

Thirteen studies reported on this outcome (figure 2A). The study by Taggart et al included 40 participants, and they discovered that asthma education could enlighten children on asthma, perceptions of asthma and the use of health services. ${ }^{33}$ Shelledy et al conducted a pilot study and included 18 participants; they found a reduction in school days missed and healthcare utilisation. ${ }^{34}$ Shaak et al included 81 patients and investigated the impact of asthma education on asthma knowledge test results, asthma control test results, healthcare use and Pediatric Asthma Caregiver's Quality of Life scores, and they suggested that the community should employ asthma education. ${ }^{35}$ The study by Safi et al found that asthma education was effective in reducing hospitalisation utilisation. ${ }^{36}$ Riera et al analysed the effect of an asthma education fair and concluded that hospitalisations remained unchanged. ${ }^{19}$ In the study of Montalvo et al, an education programme, Children's RESPIRA Education Program, was successful in reducing hospitalisation visits. ${ }^{37}$ Marshall et al organised a multicomponent programme called Reducing Ethnic/ Racial Asthma Disparities in Youth and found a positive effect on hospitalisations. ${ }^{38}$ Lebras-Isabet et al conducted a retrospective study and found that asthma education for children was useful in reducing hospitalisation. ${ }^{39}$ Condren and Boger found that multidisciplinary asthma education reduced hospitalisation by $82 \%$ and ED visits by $81 \% .^{40}$ Davis et al found that asthma education for children could help with improving the knowledge of parents and guardians on asthma, and at the same time, it could reduce inpatient admissions. ${ }^{41}$ Espinoza-Palma et al conducted full education, as well as implemented a self-management plan, which could reduce hospitalisation and further rehospitalisations. ${ }^{42}$ Broquet et al conducted a prospective study and found that interactive asthma education could improve clinical outcomes, including reducing hospitalisations. ${ }^{43}$ Johnson et al conducted a library-site asthma education programme that decreased asthma-related ED visits and hospitalisations. ${ }^{44}$ This study showed that the asthma education group had a decreased risk of hospitalisation than the other two groups $(\mathrm{RR}=0.46,95 \% \mathrm{CI}$
0.32 to 0.66 ). The study by Condren and Boger had a significantly different result; thus, we conducted a sensitivity analysis, and the result did not change ( $\mathrm{RR}=0.41,95 \% \mathrm{CI} 0.29$ to 0.58 ).

\section{Assessment of the effect of asthma education on emergency room visits}

Thirteen studies reported on this outcome (figure 2B). Apart from the above-mentioned studies, Julian et al organised therapeutic education programmes and found that ED visits decreased significantly. ${ }^{45}$ This study showed that the asthma education group had a decreased risk of ED visits than the other two groups ( $R R=0.69,95 \%$ CI 0.59 to 0.81 ).

\section{Assessment of the effect of asthma education on clinic visits}

Six studies reported on this outcome (figure 2C). The study by Calvo et al found no reduction in hospitalisation, but the number of annual clinic visits decreased. ${ }^{46}$ This result showed that the asthma education group had a decreased risk of clinic visits than the other two groups $(\mathrm{RR}=0.79,95 \%$ CI 0.58 to 1.09), but the result was not significant. The study by Shelledy et al had a significantly different result; thus, we conducted a sensitivity analysis, and the result showed that asthma education could reduce the number of clinic visits significantly $(R R=0.80$, $95 \%$ CI 0.67 to 0.97 ).

\section{Assessment of the impact of participants and setting on hospitalisation}

As shown in online supplemental figure 2, asthma education targeted at both children and parents/guardians could significantly reduce hospitalisation ( $\mathrm{RR}=0.38,95 \% \mathrm{CI} 0.24$ to 0.59 ), while asthma education targeted at only children or parents/guardians did not result in a significant change ( $R R=0.69,95 \% \mathrm{CI} 0.32$ to 1.48$)$. The result also showed that asthma education held in hospital $(\mathrm{RR}=0.49$, $95 \%$ CI 0.29 to 0.82 ) or in non-hospital settings ( $R R=0.41,95 \%$ CI 0.23 to 0.73 ) did not affect hospitalisation.

\section{Assessment of the impact of participants and setting on ED visits}

As shown in online supplemental figure 2, asthma education targeted at both children and parents/guardians $(\mathrm{RR}=0.69,95 \%$ CI 0.57 to 0.83 ) or just children or parents/guardians $(\mathrm{RR}=0.68$, 

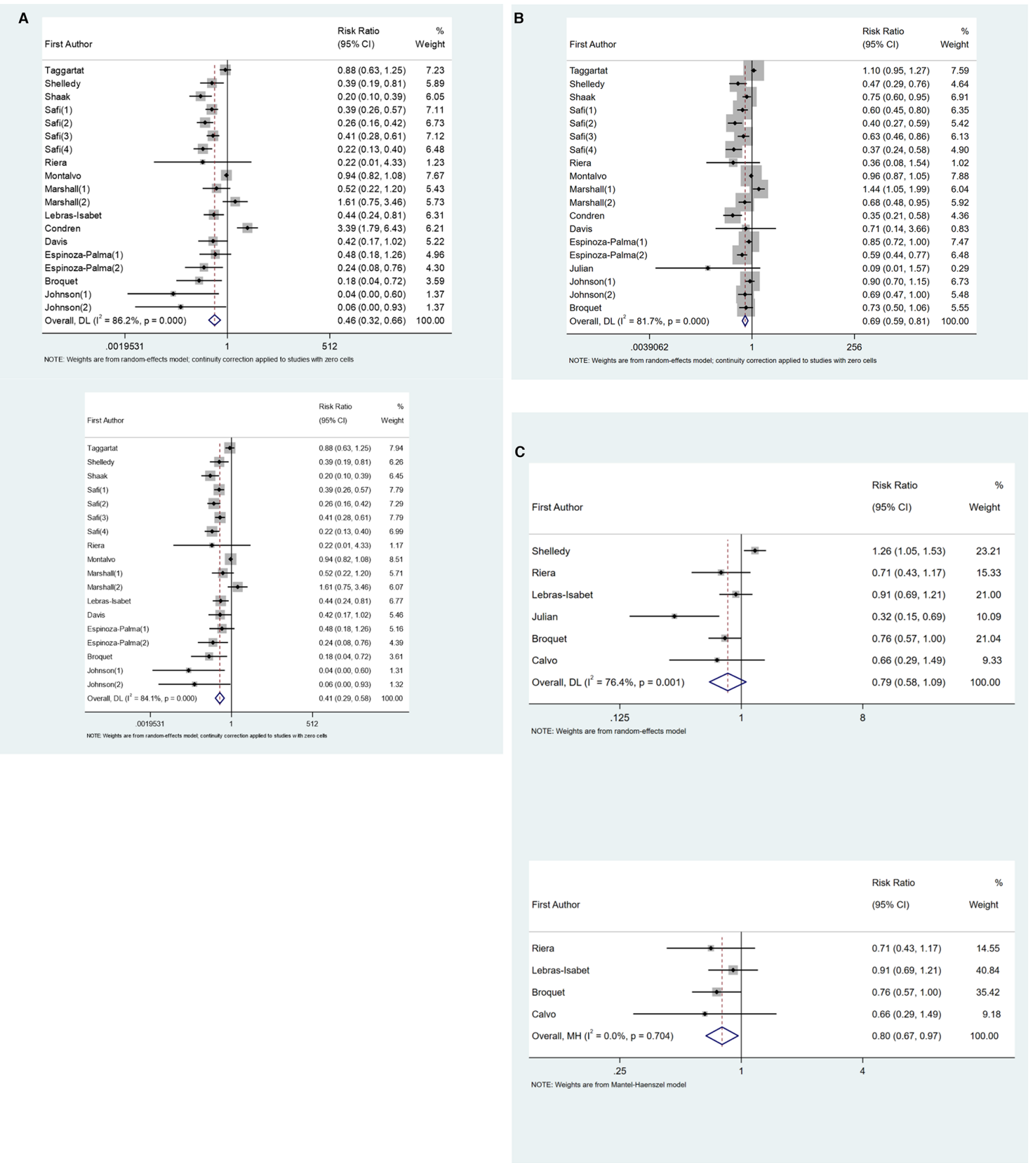

Figure 2 (A) The results of the forest plot of the effect of asthma education on hospitalisation. (B) The results of the forest plot of the effect of asthma education on emergency department visits. (C) The results of the forest plot of the effect of asthma education on clinic visits.

95\% CI 0.48 to 0.97 ) can significantly reduce ED visits. The result also showed that asthma education held in hospital $(\mathrm{RR}=0.58,95 \% \mathrm{CI} 0.44$ to 0.77$)$ or non-hospital settings $(\mathrm{RR}=0.81,95 \%$ CI 0.68 to 0.97$)$ may significantly reduce the number of ED visits.

\section{Assessment of the impact of participants and setting on clinic visits}

As shown in online supplemental figure 2, asthma education targeted at both children and parents/guardians $(\mathrm{RR}=0.74,95 \%$ CI 0.45 to 1.22 ) or just children or parents/guardians $(\mathrm{RR}=0.86$, 95\% CI 0.67 to 1.10 ) was not significantly associated with a reduction in clinic visits. The result also showed that asthma education held in hospitals $(\mathrm{RR}=0.45,95 \% \mathrm{CI} 0.22$ to 0.92$)$ can significantly reduce clinic visits, while that held in non-hospital settings ( $R R=0.92,95 \%$ CI 0.69 to 1.23 ) may not significantly reduce clinic visits. Because there were only 6 studies out of 15 which included this outcome, hence sample size was too small to detect a difference.

\section{Publication bias}

The funnel plot is shown in online supplemental figure 1. Egger's test was used to assess the publication bias of the included studies. The results indicated a substantial publication bias for included studies related to hospitalisations $(p=0.023)$, ED visits $(\mathrm{p}=0.005)$ and clinic visits $(\mathrm{p}=0.004)$. 


\section{GRADE summary of findings table}

Table 1 presents a summary of the findings and an assessment of GRADE (Grades of Recommendation, Assessment, Development,and Evaluation) for each outcome. The quality of evidence from the included studies was rated as moderate overall.

\section{DISCUSSION}

\section{Clinical implications}

To the best of our knowledge, this is the first systematic review and meta-analysis to investigate the associations between asthma education and hospitalisation, ED visits and clinic visits of children. The study results suggested that asthma education was associated with $54 \%$ lower hospitalisation risk (95\% CI 0.32 to 0.66 ) and 31\% lower ED visit risk (95\% CI 0.59 to 0.81 ) than usual care. Sensitivity analysis showed that the asthma education group had a lower clinic visit risk $(\mathrm{RR}=0.80,95 \% \mathrm{CI} 0.67$ to 0.97). This decrease suggested that asthma was better controlled after an educational intervention.

Asthma is burdensome for children globally, and better diagnostics and management are needed particularly in low/middleincome countries, due to the growing prevalence of asthma. ${ }^{47}$ The content of asthma education is related to inhaler technique assessment, written asthma treatment plans, self-monitoring of symptoms and regular medications. ${ }^{4-50}$ Poor compliance is a major obstacle to the treatment of any chronic disease. ${ }^{51}$ There are mainly two reasons behind the poor compliance: the first one is the poor understanding of the disease due to lack of knowledge or lack of communication between the doctors and patients, and the other is the deliberate decision by the patient to not follow the treatment or find an alternative method of treatment. ${ }^{52}$ Through asthma education, children can overcome poor compliance related to the first reason; this result was inconsistent with the results of the study by $\mathrm{Ng}$ et al. ${ }^{51}$ While asthma education can help control asthma in several cases, it still cannot achieve the desired result if it fails to consider the real-life scenario due to non-adaptation to targeted participants or the enrolment of several children with moderate or severe asthma. ${ }^{53}$

The asthma education intervention may be limited to children or both children and their parents or guardians. Educational interventions can take place in hospitals, at home and in the community. The subgroup analysis of our study showed that asthma education involving both children and parents/guardians was associated with decreased hospitalisations $(\mathrm{RR}=0.38,95 \%$ CI 0.24 to 0.59 ) and $\mathrm{ED}$ visits ( $\mathrm{RR}=0.69,95 \% \mathrm{CI} 0.57$ to 0.83 ). Asthma education carried out in a hospital or non-hospital setting can reduce hospitalisations and ED visits. However, for clinic visits, only asthma education carried out in hospital settings could reduce the risk ( $R R=0.45,95 \%$ CI 0.22 to 0.92). Parent involvement in education is good for the learning behaviour and emotional health of children ${ }^{54}$; thus, based on our findings, asthma education involving both children and parents can increase compliance to asthma guidelines.

\section{Methodological considerations}

The findings were limited because of the following: first, the children could learn how to deal with asthma through some other sources of information over time; it is a kind of Hawthorne effect, and the findings of this study should be interpreted cautiously. Second, we did not conduct subgroup analysis according to different teaching tools, content, frequency and educators, and it is important to conduct further analysis about these factors to get a better understanding of asthma education. Third, the outcome for this review is on reduction of hospitalisation, ED and clinic visits hence it is about asthma exacerbation which can be objectively identified in studies in the systematic review; however, not all of the included studies described adherence to therapy after education, what daily symptoms were after education and how this translated to quality of life; the future studies about these topics are also needed. Finally, further studies on different stages of asthma are needed in the future.

\section{CONCLUSION}

Asthma education is effective for controlling asthma; in particular, it is effective for reducing hospital admissions, ED visits and clinic visits. Education involving both children and parents/ guardians works better than that involving only children. The setting of asthma education has no significant impact on the effect, especially for hospitalisation and ED visits. Clinically, understanding the effect of education on asthma is critical for applying adequate preventive measures to control the prevalence of asthma in children. Furthermore, the subgroup analysis of the participants and the context of education is also useful in understanding the overall impact of education on asthma.

Contributors $\mathrm{W}-\mathrm{YL}, \mathrm{ZL}$ and $\mathrm{T}-\mathrm{HT}$ conducted the study and drafted the manuscript. $W-Y L$ and $Z L J$ participated in the design of the study and performed data synthesis. $\mathrm{W}-\mathrm{YL}$ and $\mathrm{T}-\mathrm{HT}$ conceived the study and participated in its design and coordination. All of the authors read and approved the final manuscript.

Funding The authors have not declared a specific grant for this research from any funding agency in the public, commercial or not-for-profit sectors.

Competing interests None declared.

Patient consent for publication Not required.

Ethics approval This study does not involve human participants.

Provenance and peer review Not commissioned; externally peer reviewed.

Supplemental material This content has been supplied by the author(s). It has not been vetted by BMJ Publishing Group Limited (BMJ) and may not have been peer-reviewed. Any opinions or recommendations discussed are solely those of the author(s) and are not endorsed by BMJ. BMJ disclaims all liability and responsibility arising from any reliance placed on the content. Where the content includes any translated material, BMJ does not warrant the accuracy and reliability of the translations (including but not limited to local regulations, clinical guidelines, terminology, drug names and drug dosages), and is not responsible for any error and/or omissions arising from translation and adaptation or otherwise.

Open access This is an open access article distributed in accordance with the Creative Commons Attribution Non Commercial (CC BY-NC 4.0) license, which permits others to distribute, remix, adapt, build upon this work non-commercially, and license their derivative works on different terms, provided the original work is properly cited, appropriate credit is given, any changes made indicated, and the use is non-commercial. See: http://creativecommons.org/licenses/by-nc/4.0/.

\section{ORCID iD}

Tao-Hsin Tung http://orcid.org/0000-0003-2097-8375

\section{REFERENCES}

1 Royal College of Physicians. Why asthma still kills: the national review of asthma deaths (NRAD)confidential enquiry report. RCP 2015 https:// www.rcplondon.ac.uk/ projects/outputs/why-asthma-still-kills

2 American Lung Association. Asthma and children fact sheet. American lung association, 2020. Available: https://www.lung.org/lung-health-and-diseases/lungdisease-lookup/asthma/learn-about-asthma/asthma-children-facts-sheet.html

3 Kearney J, Everson L, Coppel J, et al. Incorporating medical students into schoolbased asthma education improves asthma knowledge in children. J Asthma 2021;58:1407-13.

4 Mitchell RJ, McMaugh A, Homaira N, et al. The impact of childhood asthma on academic performance: a matched population-based cohort study. Clin Exp Allergy 2022;52:286-96.

5 Stratakis N, Garcia E, Chandran A. The role of childhood asthma in obesity development: a nationwide U.S. multi-cohort study. Epidemiology 2021

6 Yu S, Guo X, Li G, et al. Gender discrepancy in the predictive effect of metabolic syndrome and its components on newly onset cardiovascular disease in elderly from rural China. BMC Geriatr 2021;21:505. 
7 Henning RJ. Obesity and obesity-induced inflammatory disease contribute to atherosclerosis: a review of the pathophysiology and treatment of obesity. Am J Cardiovasc Dis 2021;11:504-29.

8 Ookeditse 0, Motswakadikgwa TR, Ookeditse KK, et al. Healthcare professionals knowledge of modifiable stroke risk factors: a cross-sectional questionnaire survey in greater Gaborone, Botswana. eNeurologica/Sci 2021;25:100365.

9 Navalpakam A, Secord E, Pansare M. The impact of coronavirus disease 2019 on pediatric asthma in the United States. Pediatr Clin North Am 2021;68:1119-31.

10 Jové Blanco A, González Roca I, Corredor Andrés B, et al. Impact of an asthma education program during admission. Hosp Pediatr 2021;11:849-55.

11 Bruzzese J-M, Sheares BJ, Vincent EJ, et al. Effects of a school-based intervention for urban adolescents with asthma. A controlled trial. Am J Respir Crit Care Med 2011;183:998-1006.

12 Guarnaccia S, Quecchia C, Festa A, et al. Evaluation of a diagnostic therapeutic educational pathway for asthma management in children and adolescents. Front Pediatr 2020;8:39.

13 Fleming M, Fitton CA, Steiner MFC, et al. Educational and health outcomes of children treated for asthma: Scotland-wide record linkage study of 683716 children. Eur Respir J 2019:54:1802309.

14 Harish Z, Bregante AC, Morgan C, et al. A comprehensive inner-city asthma program reduces hospital and emergency room utilization. Ann Allergy Asthma Immunol 2001;86:185-9.

15 Davis J, Fitzmaurice L. Providing individualized written asthma action plans during the pediatric emergency department visit. J Asthma 2021:58:819-24.

16 Wang L, Timmer S, Rosenman K. Assessment of a University-Based outpatient asthma education program for children. J Pediatr Health Care 2020 :34:128-35.

17 Eakin MN, Zaeh S, Eckmann T, et al. Effectiveness of a Home- and school-based asthma educational program for head start children with asthma: a randomized clinical trial. JAMA Pediatr 2020;174:1191-8.

18 Arıkan-Ayyıldız Z, Işık S, Çağlayan-Sözmen Şule, et al. Efficacy of asthma education program on asthma control in children with uncontrolled asthma. Turk J Pediatr 2016;58:383-8.

19 Riera A, Ocasio A, Goncalves P, et al. Findings from a community-based asthma education fair for Latino caregivers. J Asthma 2015;52:71-80.

20 Page MJ, McKenzie JE, Bossuyt PM, et al. The PRISMA 2020 statement: an updated guideline for reporting systematic reviews. Syst Rev 2021;10:89.

21 Chi C-C, Chen T-H, Wang S-H, et al. Risk of suicidality in people with psoriasis: a systematic review and meta-analysis of cohort studies. Am J Clin Dermatol 2017:18:621-7.

22 Wells GA, Shea B, O'Connell D. The Newcastle-Ottawa scale (NOS) for assessing the quality of Nonrandomised studies in meta-analysis. Available: http://www.ohri.ca/ programs/clinical_epidemiology/oxford.asp [Accessed 24 Mar 2015].

23 Horner SD, Brown A, Brown SA, et al. Enhancing asthma self-management in rural school-aged children: a randomized controlled trial. J Rural Health 2016;32:260-8.

24 Suwannakeeree P, Deerojanawong J, Prapphal N. School-Based educational interventions can significantly improve health outcomes in children with asthma. J Med Assoc Thai 2016;99:166-74.

25 Velsor-Friedrich B, Militello LK, Richards MH, et al. Effects of coping-skills training in low-income urban African-American adolescents with asthma. J Asthma 2012:49:372-9.

26 Clark NM, Feldman CH, Evans D, et al. The impact of health education on frequency and cost of health care use by low income children with asthma. J Allergy Clin Immunol 1986;78:108-15.

27 Kelly CS, Morrow AL, Shults J, et al. Outcomes evaluation of a comprehensive intervention program for asthmatic children enrolled in Medicaid. Pediatrics 2000; 105:1029-35.

28 Sockrider MM, Abramson S, Brooks E, et al. Delivering tailored asthma family education in a pediatric emergency department setting: a pilot study. Pediatrics 2006;117:5135-44.

29 Brown MD, Reeves MJ, Meyerson K, et al. Randomized trial of a comprehensive asthma education program after an emergency department visit. Ann Allergy Asthma Immunol 2006;97:44-51.

30 Garvey NJ, Stukel TA, Guan J, et al. The association of asthma education centre characteristics on hospitalizations and emergency department visits in Ontario: a population-based study. BMC Health Serv Res 2014;14:561.

31 Gaudreau K, Stryhn H, Sanford C, et al. Use of emergency departments and primary care visits for asthma related conditions in the 3 years following an asthma education program. J Asthma 2014:51:288-93.
32 Higgins JPT, Thompson SG, Deeks JJ, et al. Measuring inconsistency in meta-analyses. BMJ 2003:327:557-60.

33 Taggart VS, Zuckerman AE, Sly RM, et al. You can control asthma: evaluation of an asthma education program for hospitalized inner-city children. Patient Educ Couns 1991;17:35-47.

34 Shelledy DC, McCormick SR, LeGrand TS, et al. The effect of a pediatric asthma management program provided by respiratory therapists on patient outcomes and cost. Heart Lung $2005 ; 334: 423-8$.

35 Shaak S, Brown K, Reichart $\mathrm{C}$, et al. Community health workers providing asthma education. J Asthma 2020:22:1-13.

36 Safi KH, Stoermer-Grossman KJ, Kidwell KM, et al. A comprehensive pediatric asthma management program reduces emergency department visits and hospitalizations. Pediatr Allergy Immunol Pulmonol 2016;29:17-23.

37 Montalvo Stanton E, Suarez B, Martinez E. Quality of life assessment after completion of a community based inner city latino asthma program: The children's respira education program. American Journal of Respiratory and Critical Care Medicine 2011;183.

38 Marshall ET, Guo J, Flood E, et al. Home visits for children with asthma reduce Medicaid costs. Prev Chronic Dis 2020;17:E11.

39 Lebras-Isabet MN, Beydon N, Chevreul K. Impact de l'action éducative des enfants asthmatiques: I'expérience de I'hôpital Robert-Debré [Outcome evaluation of education in asthmatic children: the Robert-Debré hospital's experience]. Arch Pediatr 2004;11:1185-90.

40 Condren M, Boger JA. Impact of a pediatric clinic-based multidisciplinary asthma education and management program. J Pediatr Pharmacol Ther 2005;10:254-8.

41 Davis L, Kreashko LM, Allison V, Developing AV. Developing, implementing, and evaluating personalized education for pediatric patients diagnosed with asthma on an observation unit. J Pediatr Health Care 2019:33:72-9.

42 Espinoza-Palma T, Zamorano A, Arancibia F, et al. Effectiveness of asthma education with and without a self-management plan in hospitalized children. J Asthma 2009;46:906-10.

43 Broquet Ducret C, Verga ME, Stoky-Hess A. Impact d'une école de l'asthme sur la consommation en soins et la qualité de vie des enfants âgés de 412 ans et de leurs parents [Impact of a small-group educational intervention for 4- to 12-year-old asthmatic children and their parents on the number of healthcare visits and quality of life]. Arch Pediatr 2013;20:1201-5.

44 Johnson CE, Johnson T, Clark H, et al. A library-site asthma education program for inner-city communities. J Asthma $2006 \because 43: 9-18$.

45 Julian V, Amat F, Petit I, et al. Impact of a short early therapeutic education program on the quality of life of asthmatic children and their families. Pediatr Pulmonol 2015;50:213-21

46 Calvo Rey C, Albañil Ballesteros R, Sanchez Martín M. Educación grupal para niños asmáticos: nuestra experiencia [Group education for asthmatic children: our experience]. An Esp Pediatr 1998;49:353-8.

47 Szefler SJ, Fitzgerald DA, Adachi Y, et al. A worldwide charter for all children with asthma. Pediatr Pulmonol 2020;55:1282-92.

48 Velsor-Friedrich B, Pigott TD, Louloudes A. The effects of a school-based intervention on the self-care and health of African-American inner-city children with asthma. J Pediatr Nurs 2004; 19:247-56.

49 Butz A, Pham L, Lewis L, et al. Rural children with asthma: impact of a parent and child asthma education program. J Asthma 2005;42:813-21.

50 Yildirim M, Griffin P, Keskinocak P, et al. Estimating the impact of self-management education, influenza vaccines, nebulizers, and spacers on health utilization and expenditures for Medicaid-enrolled children with asthma. J Asthma 2021;58:1637-47. doi:10.1080/02770903.2020.1821056

$51 \mathrm{Ng}$ DKK, Chow P-Y, Lai W-P, et al. Effect of a structured asthma education program on hospitalized asthmatic children: a randomized controlled study. Pediatr Int 2006:48:158-62.

52 Hussey LC, Gilliland K. Compliance, low literacy, and locus of control. Nurs Clin North Am 1989:24:605-11.

53 Shields MC, Griffin KW, McNabb WL. The effect of a patient education program on emergency room use for inner-city children with asthma. Am J Public Health 1990;80:36-8

54 Zhang X. Barriers and benefits of primary caregivers' involvement in children's education during COVID-19 school closures. Int J Disaster Risk Reduct 2021:66:102570 